\title{
A Research Framework on Social Networking Sites Usage: Critical Review and Theoretical Extension
}

\author{
Kathy Ning Shen and Mohamed Khalifa \\ University of Wollongong in Dubai, PO Box 20183, Dubai, United Arab Emirates \\ \{kathyshen, mohamedkhalifa\} @uowdubai.ac.ae
}

\begin{abstract}
Despite the worldwide popularity and rapid proliferation of social networking sites (SNS), e.g., Facebook, our understanding about what drive people to SNS and how they use them remains limited. This study aims at establishing a theoretical framework guiding the research on SNS usage. Built upon the Theory of Acceptance and Use of Technology (UTAUT), the framework makes following major extensions: 1) taking a feature-centric perspective in conceptualizing SNS usage; 2) adopting uses and gratifications paradigm to specify the performance expectancies; 3 ) accounting for the other important social influences (identification and group norms); 4) accounting for the role of anticipated emotions; and 5) accounting for habituation by including prior usage.
\end{abstract}

Keywords: Social networking sites; post-adoptive behavior; use and gratification theory; social influences; goal-oriented behavior.

\section{Introduction}

According to Boyd and Ellison [1], social networking sites (SNS) are "web-based services that allow individuals to 1) construct a public or semi-public profile within a bounded system, 2) articulate a list of other users with whom they share a connection, and 3) view and traverse their list of connections and those made by others within the system." Since their introduction, SNS, e.g., Facebook, MySpace, and Hi5, have been rapidly expanding and profoundly affecting our society. They have become an inescapable part of our lives, which is more evident among young people. In the past couple of years alone, SNS such as Frienderster, MySpace, and Facebook have become immensely popular among adolescents and emerging adults, and play an important role in shaping their identities, affecting psychological well-being, and changing their social networks [2-4].

While most people take such technologies for granted, our understanding about SNS is very limited [2]. First, most existing studies on SNS remain descriptive, focusing on what people do with SNS and user-reported reasons for using those sites, e.g., $[2,3]$. Little research has strived for establishing causal claims, which prevents designing effective interventions for SNS. Secondly, despite the abundant research on IT adoption in general, our understanding about the post-adoptive behavior is still at the early stage [5]. Moreover, the uniqueness of SNS from the other IT applications may requires and also gives rise to further theoretical extension. 
In this study, we try to address these issues related to SNS usage by developing a theoretical framework that extends the existing IT adoption theories, e.g., the Theory of Acceptance and Use of Technology (UTAUT) [6], to accounts for the uniqueness of SNS usage. Particularly, the proposed framework advances research on SNS in several ways. First, by taking a feature-centric perspective rather than considering IT as a black-box, we focus on the pattern of SNS usage, i.e., diversified interaction between users and features in SNS. Secondly, the resulting framework extends the existing theories to capture the specificity in social computing contexts of SNS by developing a more comprehensive conceptualization of social influences. Thirdly, different from the most prior studies on SNS that are descriptive and exploratory, this study attempts to establish a base theory to explain the antecedents of SNS usage, which can readily guide future empirical research to uncover the causality in SNS usage in particularly and the other similar Internet applications in general.

The article is organized as follows. The second session will offer a critical review on IT adoption/usage and identify the theoretical gaps. Then the theoretical framework is proposed and discussed. Finally, we conclude the article by discussing the implications and possible future research opportunities.

\section{A Critical Review: Research on IT Adoption/Usage}

Since SNS are a kind of IT applications, of particularly relevant to the research on this phenomenon might be existing studies examining the adoption and use of new IT applications [6], which has evolved into one of the richest and most mature research streams in Information Systems (IS) field. There are five competing perspectives, which share much in common. The first one originates from the theory of reasoned action (TRA) [7], which predicts behavior as a function of behavioral intention depending upon attitude toward behavior and subjective norm. David [8] applied this theory to explain individual acceptance of technology and developed the Technology Acceptance Model (TAM) and TAM2 [9], which predicts information technology acceptance and usage on the job with perceived usefulness, perceived ease of use, and subjective norm. Ajzen [10] extended TRA by adding the construct of perceived behavioral control and the resulting theory, the Theory of Planned Behavior (TPB), has also been widely used to explain usage of various technologies. The second perspective in IT acceptance and usage research is from motivational theories. Davis et al. [11] explained new technology adoption and use with extrinsic and intrinsic motivation (see also [12]). The third perspective relies on Rogers' [13] Innovation Diffusion theory (IDT), which has been used to explain different innovations. In the context of IT adoption and usage, the predictive validity of innovative characteristics, e.g., relative advantage, visibility, compatibility, results demonstrability and ease of use, were supported [14]. The forth competing perspective is largely derived from Triandis' theory of interpersonal behavior [15]. According to this theory, behavior in any situation is a function of the intention, the habitual responses, and the situational constraints and conditions. Since this theory is developed to explain the choice behavior, in the context of IT adoption and usage, its direct application is limited. Most frequently, only selected constructs, e.g., perceived consequences [16], are adopted and integrated with TPB and/or TRA to explain IT adoption and usage. The fifth 
perspective takes roots in social cognitive theory [17]. Compeau and Higgins [18] applied this theory to the context $t$ of computer utilization. In this theory, expectations, self-efficacy, affect and anxiety are proposed to influence the computer usage. Realizing the overlaps among the above fifth perspectives, Venkatesh et al. [6] synthesize these prominent theories into the Unified Theory of Acceptance and Use of Technology (UTAUT) that capture the essential elements of established models into four core predictors, i.e., performance expectancy, social influences, effort expectancy, and facilitating conditions.

Although insightful, certain theoretical gaps remain in applying existing theories directly to SNS. First, much of this research has been focusing on the initial adoption of IT and the reflective cognitive processing (e.g., a technology's usefulness and ease of use) associated with individuals' pre-adoption activities, the adoption decision, and initial use behavior. However, the usage of SNS goes beyond the initial adoption stage and should be considered as post-adoptive behavior which may not be fully explained by existing theories [5]. Particularly, the Information Systems literature has argued that rational task-technology fit models might better explain pre-adoption and adoption behaviors while political and learning models might better explain postadoptive behaviors [19]. Secondly, IT applications in such studies are more considered as a black box rather than as a collection of specific features sets; while SNS integrate various features, which in the social construction of technology [20-22] are interpreted differently by individual users. Since it is specific features that influence and determine the outcomes [21], it is necessary to take a feature-centric view of technology [5] in examining SNS. Thirdly, emphasizing on the reflective cognitive processing, most prior research on IT usage has overlooked the role of emotions in affecting user behavior [23]. Recent research shows that negative anticipated emotions influence the individual's intentions over and above the cognitive variables [24]. According to the model of goal-oriented behavior [23], individual users tend to take into account the emotional consequences, termed as anticipated emotions. Finally, developed in the context of organizational IS, most existing theories, e.g., the Unified Theory of Acceptance and Use of Technology (UTAUT) [6], may not be able to capture the specificity of social computing applications such as SNS. For instance, while the equivocal results have been reported regarding the effect of social influences on IT usage in organizational contexts [6], social influences are frequently cited as an influential factor in social computing contexts [25].

Recently, some theoretical advancement has been made to address the above gaps. Taking a feature-centric view, Jasperson et al. [5] proposed the construct of postadoptive behavior in the context of IT-enabled work systems, defined as the "myriad feature adoption decisions, feature use behaviors, and feature extension behaviors made by an individual user after an IT application has been installed, made accessible to the user, and applied by the user in accomplishing his/her work activities" (pp. 531). It is a function of prior usage and individual cognitions, contingent upon individual differences. Prior usage accounts for the impact of habituation, which also echoes the argument made by Triandis [15] that behavior in any situation is a function partly of the habitual responses. Individual cognitions involve both processes and content. According to Jasperson et al., the four predictors in UTAUT capture the cognitive content and are more likely to influence post-adoptive intentions. However, Jasperson, et al's model remains a conceptual work, lack of empirical support. 
Moreover, their theory is developed for working systems which are significantly different from SNS. For instance, while the contextual influences in [5] are mainly from organizations; in SNS, from various social sources. While the expectations in the context of work systems are mainly related to work performance; those in SNS are far more diversified. While the post-adoptive behavior in the context of work systems might be mandatory; that in SNS is completely voluntary. Finally, incorporating UTAUT predictors fails to account for the role of emotions in affecting user behavior, as discussed above.

Based the critical literature review, we anchor our research framework with UTAUT and Jasperson et al.'s work [5] because these two theories represent the upto-date and comprehensive understanding of IT acceptance and usage, covering from acceptance, initial usage to post-adoption stages. However the limitations in these theories suggest further theoretical development remain relevant and necessary to account for the specificity of SNS.

\section{Theoretical Framework on SNS Usage}

In this section, we will discuss the conceptual framework (See Figure 1) explaining antecedents of SNS usage. The overarching theory explaining the antecedents is the UTAUT [6]. The main extensions of the UTAUT are: 1) taking a feature-centric perspective [5] in conceptualizing SNS usage; 2) specifying the performance expectancies by adopting uses and gratifications paradigm which has been widely used in explaining media usage [26]; 3) accounting for the other important social influences (identification and group norms) [27]; 4) accounting for the role of anticipated emotions [23]; and 5) accounting for habituation by including prior usage [5, 15].

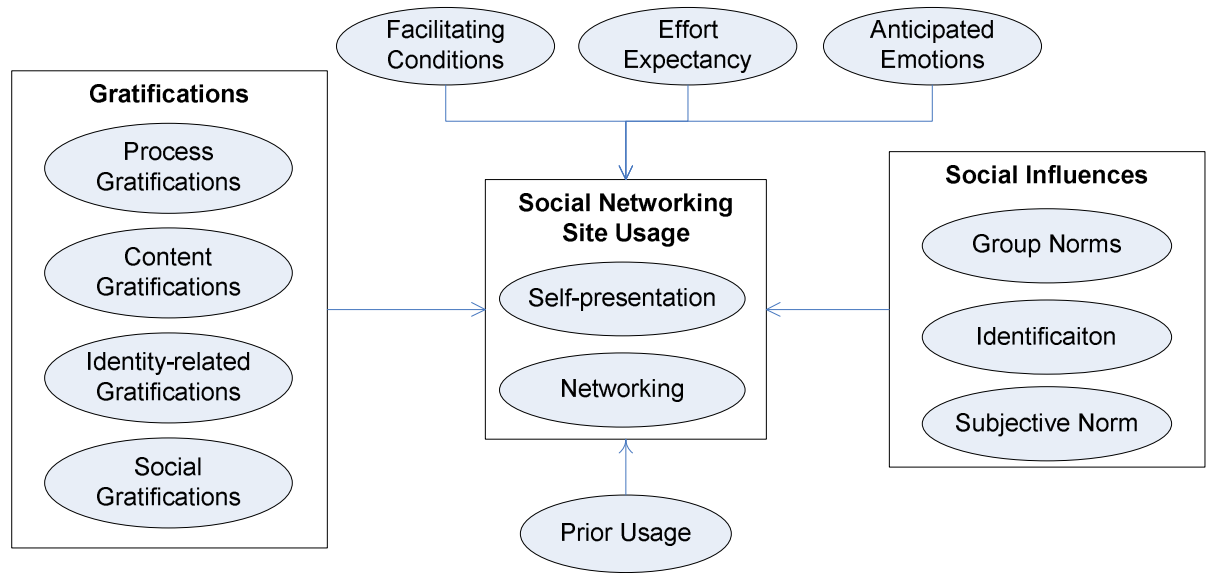

Fig. 1. Theoretical Framework

Due to its integrated technical context, it is not appropriate to assume usage of SNS as uni-dimensional. According to the definition by Boyd and Ellison [1], SNS usually provide three functions, i.e., self-presentation, social networking, and information 
sharing, from which we derive the usage behaviors that are relevant for SNS. First, self-presentation refers to a person's effort to express a specific image and identity to others [28]. Users may follow different strategies in presenting themselves, e.g., Authentic, Authentic Ironic and Fakesters [29]. By using different features, users may determine the level of identity information discloser (ranging from screen names only to full-fledged profiles) as well as enforce access control (from open to public to completely private). As for networking, it refers to a person's effort to develop and maintain his/her social networks, as indicated through the quantitative characteristics (the amount of connections), the nature of networks (who are connected), networking activities (e.g., cross-posting and sending/receiving invitations).

Synthesizing eight prominent models, the UTAUT [6] articulates four strong predictors for use behavior, i.e., performance expectancy, social influences, effort expectancy, and facilitating conditions.

Performance expectancy is defined as the degree to which an individual believes that using the system will help him or her to attain gains in job performance. Although SNS may not be related to job performance, applicable is the same logic that positive utilitarian expectancies lead to more usage [30]. To account for the specificity of SNS, we rely on the uses and gratifications paradigm (U\&G) to identify a set of relevant expectancies. According to the U\&G [26], individuals interact with media in a goal-oriented fashion to fulfill a core set of motives or gratifications, which are similar to performance expectancies. This theory has been applied to study Internet usage because of the Internet and its applications' media-like characteristics [26, 31]. Since SNS are a typical Internet application, we also adopt the similar approach. In [26], three categories of gratifications were identified and empirically validated, i.e., process, content and social, covering both website interaction and social interaction. Although more comprehensive than the other typologies, these gratifications fail to capture the ones related to identity-related motives. SNS have been portrayed to be a great venue for people to look for self [32-34]. Existing research on motivation has suggested some identity-related motives, such as feared and/or desired selves [35], self-verification [36], self-enhancement [25, 37], and self-exploration [33]. Thus, we incorporate identity-related gratifications into the original set of gratifications proposed by [26] and, together, they specify the performance expectancies in SNS.

Another major extension of the UTAUT is to account for multiple routes for social influences [27]. While UTAUT only focuses on subjective norm which is a normative influence of others' expectations, individual behavior is also subject to the other two group-level influences, i.e., internalization (i.e., congruence of one's goals with those of group members), and identification (i.e., conception of one's self in terms of the group's defining features). The effects of these three social influences have been examined in the context of virtual communities [38]. Although virtual communities examined in [38] are built around content while SNS, around users, social influences remain relevant.

The third extension of the UTAUT is to account for the role of emotions in affecting use behavior. Anticipated emotions are derived from the model of goal-oriented behavior [23] and defined as prefactual appraisals in which the individual imagines the emotional consequences of achieving and not achieving a goal. The forwardlooking positive emotions when the users imagine the pleasant aspects of the upcoming experience from using SNS will significantly predict the actual usage. 
The forth extension of the UTAUT is to account for habituation by including prior usage, defined as existing experiences with certain SNS features. It is suggested that as individuals gain experience with what was initially a novel behavior (e.g., first usage of a SNS), they tend to engage less frequently in reflective processes and simply reply on previous patterns of behavior to direct future behavior [39, 40]. Accordingly, for most regular users of SNS, their interaction is likely to reflect a habitualization of action that occurs more or less automatically [5, 41].

The last two predictors according to UTAUT are effort expectancy and facilitating conditions. Effort expectancy refers to the degree of ease associated with the use of the system (in this case, a SNS). Facilitating conditions are defined as the degree to which an individual believes that an organizational and technical infrastructure exists to support use of the system. In SNS, facilitation may come from online help offered by the site itself, or the other users of the same site, which removes barriers to use. We adapt the same conceptualizations in SNS not at the system level, but at the feature level to be consistent with the feature-centric perspective. Some features are easier to use than the others. The more facilitating conditions perceived by the users regarding specific features, the more likely they extend the usage of those features.

\section{Implications and Future Research}

In this study, we attempted to extend the existing theories to explain SNS usage by: 1) taking a feature-centric perspective in conceptualizing SNS usage; 2) adopting uses and gratifications paradigm to specify the performance expectancies; 3) accounting for the other important social influences (identification and group norms); 4) accounting for the role of anticipated emotions; and 5) accounting for habituation by including prior usage. The proposed framework entails significant theoretical and practical implications.

First, by conceptualizing SNS usage as post-adoptive behavior at the feature level, our framework will better uncover the complexity in SNS usage. While most information systems have integrated various features along with different users' appropriation, same information system may generate distinct usage patterns and interpretations. Although the framework focuses on SNS usage, the same approach should be applied in investigating information systems in general. Second, built upon the UTAUT [6] and Jasperson et al.'s work [5], the proposed framework provides a more integrated understanding about the antecedents of SNS usage by accounting for both cognitive and affective factors, both rational and habitual reasons, and both personal and social influences. Again, we believe that this integrated approach will be useful in investigating the other social computing systems. Finally, the proposed framework is ready to guide further hypothesis development and empirical validation, which will well complement the void of research on causality in SNS research. Particularly, while the majority studies were conducted with US/European samples, limited understanding has been achieved outside the developed countries. Given the rapid increase in SNS usage in regions such as Asia and Middle East where people may use SNS for different purposes, and the SNS usage may incur different implications. Therefore, we encourage researchers to examine the samples in various cultural/national contexts and to bring the local specificities into the SNS research. 
In terms of future extension, we would suggest considering important moderators, such as gender and culture. For instance, prior research has realized the gender differences in affecting users' interaction with IT (e.g., [42-45]. In the context of SNS gender differences may be present in following ways. First, although the existing evidence has not uncovered significant gender differences in the amount of usage of SNS; but gender differences were reported in the pattern of usage. For instance, Manago et al. [46] reported that male-female differences in self-presentation parallel, and possibly intensify, gender norms offline. Similarly, Magnuson and Dundes [47] reported that some traditional gender roles also exhibit online in SNS, as indicated by different patterns in their user profiles. Fogel and Nehmad [48] reported general privacy concerns and identity information disclosure concerns are of greater concern to women than men. Greater percentages of men than women display their phone numbers and home addresses on SNS; and greater risk taking attitudes exist among men than women. Second, gender has been identified as one of major moderators in UTAUT [6]. Significant gender differences were reported for the effects of performance expectancy, effort expectancy, and social influences. The effect of performance expectancy is stronger for men than women; while that of effort expectancy and social influences is stronger for women than men. Particularly, Thelwall [49] reported in MySpace, females are more interesting in friendship, males are more interested in dating. Given strong cultural notions of gender, there is no reason to assume equal adoption and pursuit of SNS between the male and female users. Moreover, investigating gender differences in SNS usage will be a gateway to explicate more complicated cultural differences.

\section{References}

1. Boyd, D., Ellison, N.B.: Social network sites: Definition, history, and scholarship. Journal of Computer-Mediated Communication 13, 210-230 (2008)

2. Pempek, T.A., Yermolayeva, Y.A., Calvert, S.L.: College students' social networking experiences on Facebook. Journal of Applied Developmental Psychology (2009)

3. Subrahmanyam, K., Reich, S.M., Waechter, N., Espinoza, G.: Online and offline social networks: Use of social networking sites by emerging adults. Journal of Applied Developmental Psychology 29, 420-433 (2008)

4. Steinfield, C., Ellison, N.B., Lampe, C.: Social capital, self-esteem, and use of online social network sites: A longitudinal analysis. Journal of Applied Developmental Psychology 29, 434-445 (2008)

5. Jasperson, J., Carter, P.E., Zmud, R.W.: A comprehensive conceptualization of postadoption behaviors associated with information technology enabled work systems. MIS Quarterly 29, 525-557 (2005)

6. Venkatesh, V., Morris, M.G., Davis, G.B., Davis, F.D.: User Acceptance of Information Technology: Toward a Unified View. MIS Quarterly 27 (2003)

7. Fishbein, M., Ajzen, I.: Belief, Attitude, Intention and Behavior: An Introduction to Theory and Research. Addison-Wesley Publishing Company, Reading (1975)

8. Davis, F.D.: Perceived Usefulness, Perceived Ease of Use and User Acceptance of Information Technology. MIS Quarterly 13, 319-340 (1989)

9. Venkatesh, V., Davis, F.D.: A Theoretical Extension of the Technology Acceptance Model: Four Longitudinal Field Studies. Management Science 46, 186-204 (2000)

10. Ajzen, I.: The Theory of Planned Behavior. Organizational Behavior and Human Decision Processes 50, 179-211 (1991) 
11. Davis, F.D., Bagozzi, R.P., Warshaw, P.R.: Extrinsic and Intrinsic Motivation to Use Computers in the Workplace. Journal of Applied Social Psychology 22, 1111-1132 (1992)

12. Venkatesh, V., Johnson, P.: Telecommuting Technology Implementations: A Within- and Between- Subjects Longitudinal Field Study. Personnel Psychology 55, 661-687 (2002)

13. Rogers, T.B.: The Psychological Testing Enterprise. Brooks/Cole Publishing Company, Pacific Grove (1995)

14. Moore, G.C., Benbasat, I.: Integrating Diffusion of Innovations and Theory of Reasoned Action Models to Predict Utilization of Information Technology by End-Users. In: Kautz, K., Pries-Hege, J. (eds.) Diffusion and Adoption of Information Technology, pp. 132-146. Chapman and Hall, London (1996)

15. Triandis, C.H.: Values, Attitudes and Interpersonal Behavior. In: Howe, H.E. (ed.) Nebraska Symposium on Motivation, 1979: Beliefs, Attitudes and Values, pp. 159-295. University of Nebraska Press, Lincoln (1980)

16. Limayem, M., Khalifa, M., Frini, A.: What Makes Consumers Buy from Internet? A Longitudinal Study of Online Shopping. IEEE Transactions on Systems, Man and Cybernetics-Part A: Systems and Humans 30, 421-432 (2000)

17. Bandura, A.: Social Foundations of Thought and Action: A Social Cognitive Theory. Prentice Hall, Englewood Cliffs (1986)

18. Compeau, D.R., Higgins, C.A.: Application of Social Cognitive Theory to Training for Computer Skills. Information Systems Research 6, 118-143 (1995)

19. Robey, D., Ross, J.W., Boudreau, M.: Learning to Implement Enterprise Systems: An Exploratory Study of the Dialectics of Change. Journal of Management Information Systems 19, 17-46 (2002)

20. Orlikowski, W.J.: The Duality of Technology: Rethinking the Concept of Technology in Organizations. Organization Science 3, 398-427 (1992)

21. Griffith, T.L.: Technology Features as Triggers for Sensemaking. Academy of Management Review 24, 472-488 (1999)

22. DeSanctis, G., Poole, M.S.: Capturing the Complexity in Advanced Technology Use: Adaptive Structuration Theory. Organization Science 5, 121-147 (1994)

23. Perugini, M., Bagozzi, R.: The role of desires and anticipated emotions in goal-directed behaviours: Broadening and deepening the theory of planned behaviour. British Journal of Social Psychology 40, 79-98 (2001)

24. Bagozzi, R.P., Dholakia, U.M., Basuroy, S.: How Effortful Decisions Get Enacted: The Motivating Role of Decision Processes, Desires, and anticipated Emotions. Journal of Behavioral Decision Making 16, 273-295 (2003)

25. Dholakia, U.M., Bagozzi, R.P., Pearo, L.K.: A Social Influence Model of Consumer Participation in Network- and Small-Group-Based Virtual Communities. International Journal of Research in Marketing 21, 241-263 (2004)

26. Stafford, T.E., Stafford, M.R., Schkade, L.L.: Determining uses and gratifications for the Internet. Decision Sciences 35, 259-288 (2004)

27. Bagozzi, R.P., Lee, K.H.: Multiple Routes for Social Influence: The Role of Compliance, Internalization, and Social Identity. Social Psychology Quarterly 65, 226-247 (2002)

28. Joinson, A.N.: Understanding the Psychology of Internet Behaviour: Virtual Worlds. Real Lives Palgrave Macmillan, New York (2003)

29. Marwick, A.: I' $m$ a lot more interesting than a Friendster profile: Identity presentation, authenticity, and power in social networking services. In: Internet Research 6.0, Chicago, USA (2005)

30. Raacke, J., Bonds-Raacke, J.: MySpace and Facebook: Applying the Uses and Gratifications Theory to Exploring Friend-Networking Sites. CyberPsychology \& Behavior 11, 169-174 (2008) 
31. Diddi, A., LaRose, R.: Getting hooked on news: Uses and gratifications and the formation of news habits among college students in an Internet environment. Journal of Broadcasting \& Electronic Media 50, 193-210 (2006)

32. Tong, S.T., Van der Heide, B., Langwell, L., Walther, J.B.: Too much of a good thing? The relationship between number of friends and interpersonal impressions on Facebook. Journal of Computer-Mediated Communication 13, 531-549 (2008)

33. Valkenburg, P.M., Schouten, A.P., Peter, J.: Adolescents' identity experiments on the internet. New Media \& Society 7, 383-402 (2005)

34. Zhao, S., Grasmuck, S., Martin, J.: Identity construction on Facebook: Digital empowerment in anchored relationships. Computers in Human Behavior 24, 1816-1836 (2008)

35. Cesario, J., Grant, H., Higgins, E.T.: Regulatory fit and persuasion: Transfer from "feeling right". Journal of Personality and Social Psychology 86, 388-404 (2004)

36. Swann Jr., W.B., Polzer, J.T., Style, D.C., Ko, S.J.: Finding Value in Diversity: Verification of Personal and Social Self-Views in Diverse Groups. Academy of Management Review 29, 9-27 (2004)

37. Pfeffer, J., Fong, C.T.: Building Organization Theory from First Principles: The SelfEnhancement Motive and Understanding Power and Influence. Organization Science 16, 372-388 (2005)

38. Bagozzi, R.B., Dholakia, U.M.: Intentional Social Action in Virtual Communities. Journal of Interactive Marketing 16, 2-79 (2002)

39. Bargh, J.A., Peitromonaco, P.: Automatic Information Processing and Social Perception: The Influence of Trait Information Presented Outside of Conscious Awareness on Impression Formation. Journal of Personality and Social Psychology 43, 437-449 (1982)

40. Verplanken, B., Aarts, H., van Knippenberg, A., Moonen, A.: Attitude versus General Habit: Antecedents of Travel Mode Choice. Journal of Applied Social Psychology 24, 285-300 (1994)

41. Khalifa, M., Limayem, M., Liu, V.: A Contingency Theory for Online Consumer Retention: the Role of Online Shopping Habit. In: Hunter, G., Tan, F. (eds.) Advanced Topics in Global Information Management, vol. 3, pp. 39-55. Idea Group Publishing, Hersey (2004)

42. Venkatesh, V., Morris, M.G.: Why Don't Men Ever Stop to Ask for Directions? Gender, Social Influence, and Their Role in Technology Acceptance and Usage Behavior. MIS Quarterly 24, 115-139 (2000)

43. Munro, M.C., Huff, S.L., Marcolin, B.L., Compeau, D.R.: Understanding and Measuring User Competence. Information \& Management 33, 46-57 (1997)

44. Gefen, D., Straub, D.W.: Gender Differences in Perception and Adoption of E-Mail: An Extension to the Technology Acceptance Model. MIS Quarterly 21, 389-400 (1997)

45. Gefen, D., Ridings, C.M.: If you spoke as she does, Sir, Instead of the Way you do: A sociolinguistics perspective of gender differences in virtual communities. The DATA BASE for Advances in Information Systems 36, 78-92 (2005)

46. Manago, A.M., Graham, M.B., Greenfield, P.M., Salimkhan, G.: Self-presentation and gender on MySpace. Journal of Applied Developmental Psychology 29, 446-458 (2008)

47. Magnuson, M.J., Dundes, L.: Gender differences in "social portraits" reflected in MySpace profiles. Cyber Psychology \& Behavior 11, 239-241 (2008)

48. Fogel, J., Nehmad, E.: Internet social network communities: Risk taking, trust, and privacy concerns. Computers in Human Behavior 25, 153-160 (2009)

49. Thelwall, M.: Social networks, gender, and friending: An analysis of MySpace member profiles. Journal of American Society for Information Science and Technology 59, 13211330 (2008) 